University of Wollongong

Research Online

Faculty of Engineering and Information

Faculty of Engineering and Information

Sciences - Papers: Part B

Sciences

2018

Low Carbon Desalination by Innovative Membrane Materials and Processes

Hung Duong

University of Technology Sydney, Le Quy Don Technical University, chd581@uowmail.edu.au

Ashley Ansari

University of Wollongong, ashleyz@uow.edu.au

Long D. Nghiem

University of Technology Sydney, longn@uow.edu.au

Thao Pham

Le Quy Don Technical University

Thang Pham

Le Quy Don Technical University

Follow this and additional works at: https://ro.uow.edu.au/eispapers1

Part of the Engineering Commons, and the Science and Technology Studies Commons

Research Online is the open access institutional repository for the University of Wollongong. For further information contact the UOW Library: research-pubs@uow.edu.au 


\title{
Low Carbon Desalination by Innovative Membrane Materials and Processes
}

\author{
Abstract \\ Seawater and brackish water desalination has been a practical approach to mitigating the global fresh \\ water scarcity. Current large-scale desalination installations worldwide can complementarily augment the \\ global fresh water supplies, and their capacities are steadily increasing year-on-year. Despite substantial \\ technological advance, desalination processes are deemed energy-intensive and considerable sources of \\ C02emission, leading to the urgent need for innovative low carbon desalination platforms. This paper \\ provides a comprehensive review on innovations in membrane processes and membrane materials for \\ low carbon desalination. In this paper, working principles, intrinsic attributes, technical challenges, and \\ recent advances in membrane materials of the membrane-based desalination processes, exclusively \\ including commercialised reverse osmosis (RO) and emerging forward osmosis (FO), membrane \\ distillation (MD), electrodialysis (ED), and capacitive deionisation (CDI), are thoroughly analysed to shed \\ light on the prospect of low carbon desalination.

\section{Disciplines} \\ Engineering | Science and Technology Studies \\ Publication Details \\ Duong, H. Cong., Ansari, A. J., Nghiem, L. D., Pham, T. M. \& Pham, T. D. (2018). Low Carbon Desalination \\ by Innovative Membrane Materials and Processes. Current Pollution Reports, 4 251-264.
}




\section{Low Carbon Desalination by Innovative Membrane Materials and} Processes

Summited to

\section{Current Pollution Reports}

Hung C. Duong ${ }^{\mathrm{a}, \mathrm{b}, *}$, Ashley J. Ansaric ${ }^{\mathrm{c}}$, Long D. Nghiem ${ }^{\mathrm{a}}$, Thao. M. Pham ${ }^{\mathrm{b}}$, and Thang D.

Pham $^{\text {b }}$

${ }^{\text {a }}$ Centre for Technology in Water and Wastewater, University of Technology Sydney, Ultimo, NSW 2007, Australia

${ }^{\mathrm{b}}$ Le Quy Don Technical University, Hanoi, Vietnam

${ }^{c}$ Strategic Water Infrastructure Laboratory, School of Civil, Mining and Environmental Engineering, University of Wollongong, Wollongong, NSW 2522, Australia 17

.

.

\footnotetext{
$21 *$ Corresponding author:
}

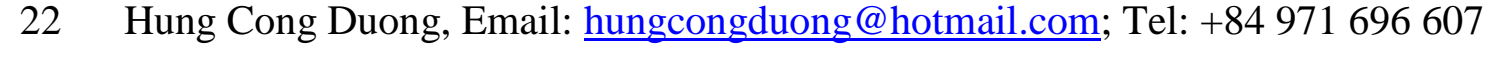


23 Abstract: Seawater and brackish water desalination has been a practical approach to mitigating 24 the global fresh water scarcity. Current large-scale desalination installations worldwide can complementarily augment the global fresh water supplies, and their capacities are steadily increasing year-on-year. Despite substantial technological advance, desalination processes are deemed energy-intensive and considerable sources of $\mathrm{CO}_{2}$ emission, leading to the urgent need for innovative low carbon desalination platforms. This paper provides a comprehensive review on innovations in membrane processes and membrane materials for low carbon desalination. In 30 this paper, working principles, intrinsic attributes, technical challenges, and recent advances in 31 membrane materials of the membrane-based desalination processes, exclusively including commercialised reverse osmosis (RO) and emerging forward osmosis (FO), membrane distillation (MD), electrodialysis (ED), and capacitive deionisation (CDI), are thoroughly analysed to shed light on the prospect of low carbon desalination.

35 Keywords: low carbon desalination; membrane-based desalination; reverse osmosis (RO); 36 forward osmosis (FO); membrane distillation (MD); electrodialysis (ED); capacitive 37 deionisation $(\mathrm{CDI})$. 


\section{Introduction}

Desalination has become a practical approach to augmenting fresh water supplies in many water-stressed areas around the world [1]. According to the International Desalination Association, desalination plants worldwide can provide more than 86.8 million cubic meters of desalinated water per day to meet the daily fresh water demand of more than 300 million people [2]. The global desalination capacity is increasing at a steadfast pace and is expected to double by 2030 given huge financial investments [3]. The global desalination market had been long time dominated by conventional thermal distillation processes such as multi-stage flash (MSF) and multi-effect distillation (MED). However, in recent decades membrane-based separation processes, particularly reverse osmosis (RO), have become the leading desalination technology and are preferable to the conventional thermal distillation for new and projected desalination installations $[1,4,5]$. Compared to conventional thermal distillation, the membrane-based processes are by far more energy efficient. For example, the energy demand of the seawater RO process has approached closely to the theoretical minimum energy demand (i.e. $0.77 \mathrm{~kW} \mathrm{~h} / \mathrm{m}^{3}$ ) and is approximately ten-folds lower than that of the conventional thermal distillation processes [6].

The substantial growth of desalination has inevitably led to mounting environmental concerns regarding to greenhouse-gas emission. Despite being the most energy efficient, the seawater RO desalination process exhibits a carbon footprint of $2.562 \mathrm{~kg} \mathrm{CO}_{2}$ per one cubic meter of fresh water product [7]. Given the current global desalination capacity of 86.8 million cubic meters of fresh water product per day, the annual carbon footprint of all desalination installations worldwide is $79 \mathrm{Mt} \mathrm{CO}_{2}$, with a potential growth of 10 to $15 \%$ per annum [4]. In this context, low carbon desalination processes are urgently needed to sustain the growth of desalination to meet increasing global fresh water demand while reducing desalination carbon footprint to reach the global $\mathrm{CO}_{2}$ emission target set in the Paris Agreement on climate change in 2015 [8].

This paper aims at providing a comprehensive review of innovative desalination membrane processes and membrane materials with respects to energy consumption and hence carbon footprint reduction. The desalination membrane-based processes discussed in this review paper include maturely commercialised RO and other emerging processes such as forward osmosis (FO), membrane distillation (MD), electrodialysis (ED), and capacitive deionisation (CDI). 
Working principles, intrinsic attributes, and technical challenges with respect to energy efficiency and decarbonisation of each process are thoroughly analysed and discussed.

\section{Reverse osmosis}

In reverse osmosis ( $\mathrm{RO})$ desalination, desalinated water is extracted from a saline solution using a semi-permeable membrane that selectively favours the permeation of water. Energy is required to push water through the membrane against the effect of the osmotic pressure gradient between the saline feed and the permeate streams. The theoretical minimum energy demand for the RO process of seawater at water recovery of $50 \%$ is $1.06 \mathrm{kWh} / \mathrm{m}^{3}$ [1]. However, the actual energy consumption of seawater RO desalination exceeds this minimum value because a hydrostatic pressure much higher than the osmotic pressure of seawater is required to obtain a desired process water flux. Pre-treatment of the feed water and post-treatment of the permeate further increase the energy consumption of RO processes compared to the theoretical minimum value. the pre-treatment step using ultra-filtration (UF) [9]. Therefore, strategies for energy consumption reduction, and hence for increased decarbonisation, of RO desalination mainly focus on reducing the energy consumption of the $\mathrm{RO}$ and the pre-treatment steps.

The energy consumption of the RO step can be reduced by increasing membrane water permeability. According to Cohen-Tanugi et al. [10], energy consumption of seawater RO can decrease by $20 \%$ when the membrane water permeability increases three folds. Thus, ultrapermeable membranes using Aquaporin, carbon nanotubes, and graphene materials have been explored and demonstrated for RO desalination [11-13]. In the RO process using these ultrapermeable membranes, water transports through the membrane under a different mechanism compared to traditional membranes. Water channels in the ultra-permeable membranes facilitate the transport of water molecules while not compromising the rejection of dissolved salts, giving the ultra-permeable membranes a much higher water permeability but a similar salt 
permeability allows for the RO desalination operation at a lower applied pressure while

100 obtaining the same process water flux, thus decreasing the process specific energy consumption

$101[1]$.

102

103

104

105

106

107

108

109

110

111

112

113

114

115

116

Process optimisation has also been approached to reduce the energy consumption and hence to decarbonise fresh water production of RO desalination. One strategy to reduce RO energy consumption is multi-staging the RO process. As demonstrated in Fig. 1, in a single-stage RO process, a minimum hydrostatic pressure $\left(\mathrm{P}_{\mathrm{H}}\right)$ equal to the osmotic pressure of the concentrate at the outlet of the RO module $\left(\Pi_{C}\right)$ is applied. Along the membrane module from the inlet, $\mathrm{P}_{\mathrm{H}}$ is higher than the local osmotic pressure (П) of the concentrate. The difference between $\mathrm{P}_{\mathrm{H}}$ and local $\Pi$ causes the irreversible energy loss. In a multi-stage RO process, more high-pressure pumps are used between RO membrane stages, and the applied pressure of each stage increases with the order of the stage. This allows the applied pressure of each stage to approach closer to the local $П$. Thus, operating the RO process in multi-stage helps reduce the irreversible energy loss and allows the RO process to approach the theoretical minimum energy consumption [1, $14,15]$. In other words, the seawater RO desalination process with infinite stages at water recovery of $50 \%$ can achieve the theoretical minimum energy consumption of $1.06 \mathrm{kWh} / \mathrm{m}^{3}$. Nevertheless, multi-staging the RO process also leads to increase in investment and operational costs as more high-pressure pumps and maintenance are required.

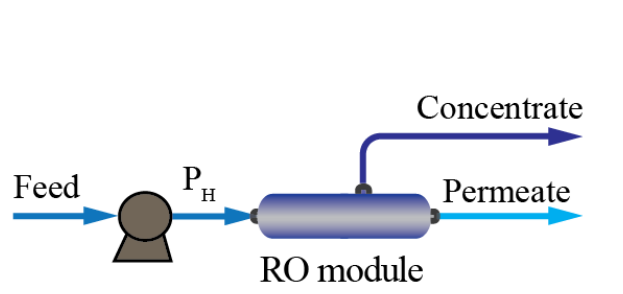

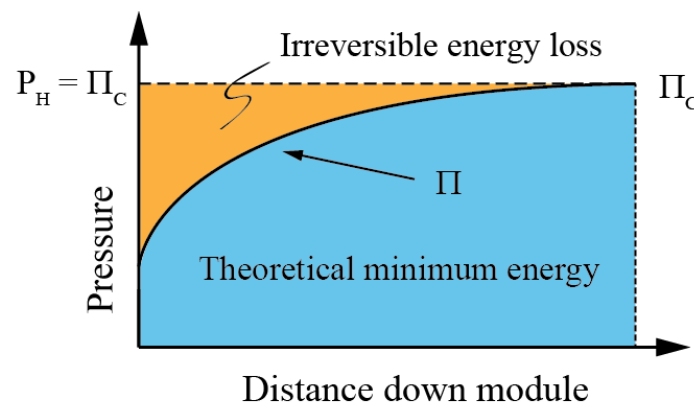

Single-stage RO

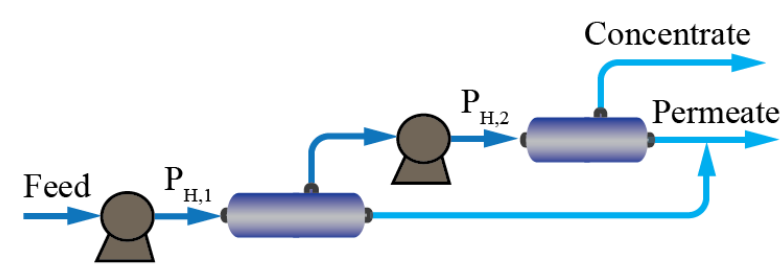

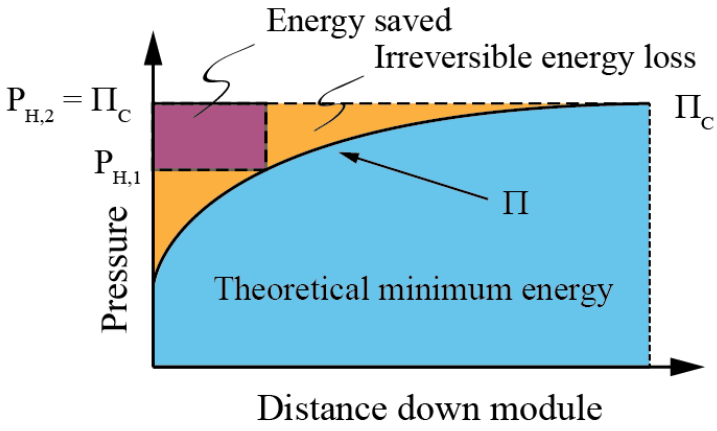

Multi-stage RO

Fig. 1. Schematic diagrams and energy saving of a single-stage and a multi-stage RO process (adapted from [1]). 
The energy consumption of RO desalination can be reduced by operating the process in closed circuit or semi-batch mode $[16,17]$. In closed circuit or semi-batch RO process, saline feed water is continuously pumped into a variable-volume high pressure vessel connected with spiral-wound RO membranes (Fig. 2). Fresh water is collected at the outlets of the membrane modules while the pressurised concentrate is circulated back to the pressure vessel to mix with the feed water. The residual pressure of the concentrate is reused to pressurise the feed water, hence reducing the applied pressure on the feed water. The pressure of the mixed feed water in the pressure vessel is increased overtime with the increase in the osmotic pressure of the mixed feed. When a desired water recovery has been achieved, the concentrated mixed feed water (i.e. brine) is discharged and replaced by fresh water feed before starting the next operation cycle. Simulation results have demonstrated that semi-batch and closed circuit operation can reduce energy consumption of a brackish water RO desalination process by $64 \%$ [16].

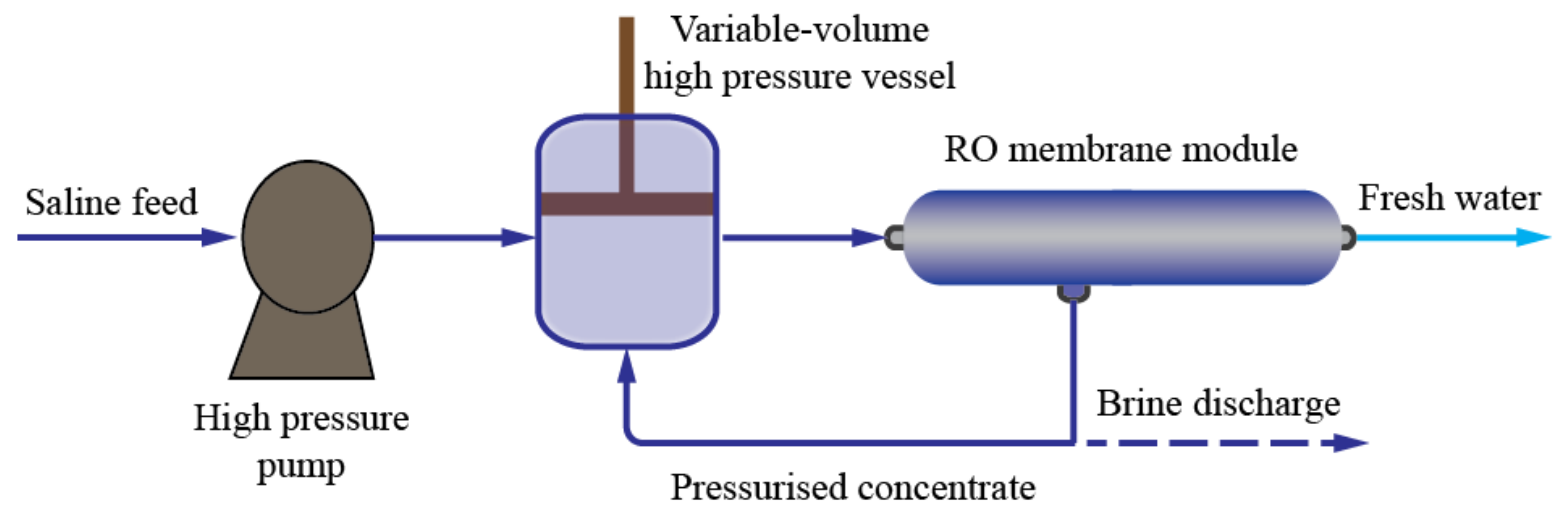

132

Fig. 2. Schematic diagram of a close circuited RO process.

Membrane fouling is an intrinsic technical issue for RO desalination. Fouling leads to decline in the process water flux or increase in the applied pressure, inevitably increasing the specific energy consumption of the RO process. Various methods have been explored to mitigate and control membrane fouling during the RO desalination process, of which pretreatment of the feed water is a prerequisite. Conventionally, media filters, low pressure UF, and probably dissolved air flotation (DAF) are incorporated before RO membrane modules to pre-treat the feed water. This pre-treatment train has proven capable of effectively removing turbidity and assimilable organic carbon (AOC), thus providing quality feed water to the RO membrane modules. However, this pre-treatment step (particularly UF) still contributes 0.3 $\mathrm{kWh} / \mathrm{m}^{3}$ to the total energy consumption of the RO process. Practising subsurface intakes (e.g. using beach wells and galleries for pre-treatment) can help reduce the energy consumption for pre-treatment and hence for the overall process of seawater RO desalination [18]. Geological 
146 properties of beach wells and galleries retain and provide biological removal of organic matter,

147 suspended sediments, and dissolved organic compounds, thus offering a cost-effective and 148 energy saving pre-treatment prior to the RO membranes [18]. Nevertheless, this pre-treatment 149 method is limited to feed waters with low a membrane fouling propensity.

150 A novel approach to reducing energy consumption of pre-treatment in RO desalination is to 151 deploy gravity driven membranes (GDM) [19-21]. In a GDM pre-treatment system, feed water 152 is dead-end filtered through UF membrane under a hydrostatic pressure regenerated by a water 153 head, obviating the need for a high-pressure pump as required in normal UF operation. A 154 beneficial biofilm consisting eukaryotic organisms formed on the UF membrane surface 155 biodegrades and hence effectively removes rejected organic particles and colloids from the feed 156 water, leading to a lower fouling potential in the subsequent RO process. The beneficial biofilm 157 also helps stabilise the water flux of the UF membrane without the need for backwash or 158 chemical cleaning. As a result, the pre-treatment energy consumption of seawater feed using 159 GDM could be markedly reduced to $0.01 \mathrm{kWh} / \mathrm{m}^{3}$ compared to $0.3 \mathrm{kWh} / \mathrm{m}^{3}$ for a normal UF 160 pre-treatment [4]. Though, GDM pre-treatment was not able to reduce dissolved organic carbon 161 content in the pre-filtered water, hence a submerged GDM system combined with carrier 162 biofilm processes was proposed for a more effective pre-treatment before the RO desalination 163 process [21].

164 In addition to reducing energy consumption, low carbon RO desalination can be achieved 165 by coupling RO with renewable energy sources such as solar, wind, and geothermal energies $166[4,5,22-24]$. Powered by renewable energy, RO desalination plants can approach to zero167 carbon emission as they can minimise the consumption of electrical energy sourced from fossil 168 fuel. Indeed, wind farms have been built beside RO desalination plants in Australia to achieve 169 carbon offset of fresh water production from seawater. However, the intermittent nature of renewable energy sources requires effective energy storage methods to prevent the frequent 171 shutdowns of the RO desalination plants. Amongst the proposed energy storage methods, grid172 scale storage based on the concept of pumped hydro and osmotic battery are particularly of 173 interest. More details about these energy storage strategies can be found elsewhere [4, 25]. 


\section{Forward osmosis}

Forward osmosis (FO) is an osmotically driven membrane process that has a number of inherent advantages for providing low carbon desalination. The significant energy benefits of FO rely on the natural osmotic pressure gradient created between the feed (source water) and draw solution (osmotic agent). This salinity gradient provides the driving force for water transport across the semi-permeable membrane, theoretically without any external energy input. The FO process also exhibits a low fouling propensity, high contaminant rejection, and can operate at high osmotic pressure driving forces, beyond the limits of RO [26]. Thus, FO is strongly suited for complex source waters that have a high fouling potential or high salinity which would otherwise not be compatible with RO treatment. Despite these advantages, an additional desalination process is required to separate fresh water from the diluted draw solute following the FO process. This fresh water extraction step can be achieved using thermal or membrane separation processes and is responsible for the majority of energy consumed in a hybrid FO process.

The most energetically favourable configuration is when FO is used as a standalone desalination process in which fresh water extracted by the FO membrane is used to dilute a draw solution for beneficial uses. The only energy requirement is the electricity to drive the water circulation pumps to minimise external concentration polarisation and membrane fouling [27]. Despite the potential for low carbon desalination, standalone FO applications have only been realised in niche areas, including fertiliser drawn [28] and sugar drawn brackish water desalination for emergency drinking relief [29]. In these applications, spontaneous water permeation from the saline water feed through the membrane dilutes the draw solution to provide a beneficial product, negating the need for high retention draw solute separation [30]. Researchers have demonstrated the potential of fertiliser drawn FO, however integration with nano-filtration (NF) is required to further dilute the draw solution and meet fertigation standards [28]. Nevertheless, the fertiliser drawn FO-NF process was found to consume $21 \%$ less energy than a UF-RO system [31]. Alternative osmotic dilution applications involve algae dewatering using seawater or RO brines, however fresh water is lost during the process [32]. The task of finding suitable draw solutions with high osmotic pressures for beneficial applications remains a major challenge for the practical adoption of standalone FO desalination. 
Apart from those standalone applications discussed above, FO must be coupled with an additional separation process to achieve complete water treatment and desalination. In other words, FO is considered as a pre-treatment step for other desalination processes such as RO, which can separate the draw solute and produce fresh water. Combined hybrid FO processes have gained attention because of the low fouling potential and superior pre-treatment that FO provides at relatively low energy. Nevertheless, because of the extensive energy requirement to separate the high osmotic pressure draw solutions, strategic selection of the source water, draw solute, and regeneration process is needed to achieve energy-savings. For example, an FO-RO hybrid system for seawater desalination (Fig. 3a) can never consume less energy than direct RO at the same recovery. Detailed equations for energy calculation of the FO-RO hybrid and the single RO desalination process can be found elsewhere [26]. Since the draw solution osmotic pressure must be greater than seawater, the minimum energy required for RO desalination is always higher for a hybrid FO-RO system. Strategically integrating wastewater treatment and seawater desalination (Fig. 3b) has been proposed to reduce the specific energy consumption of RO $[33,34]$. Using wastewater as the feed solution to dilute the seawater draw solution has resulted in lower costs compared to conventional seawater desalination with $\mathrm{RO}$, mostly due to the reduced RO operating pressure [35]. To illustrate, the estimated specific energy consumption for a low pressure FO-RO system ranges between 1.3 and $1.5 \mathrm{kWh} / \mathrm{m}^{3}$, which is significantly less than the conventional RO process (i.e. $2.2 \mathrm{kWh} / \mathrm{m}^{3}$ ) [36]. Despite this potential, FO membrane fouling, low water flux and issues regarding system scale-up remain significant challenges for full-scale implementation of FO hybrid systems.

a)

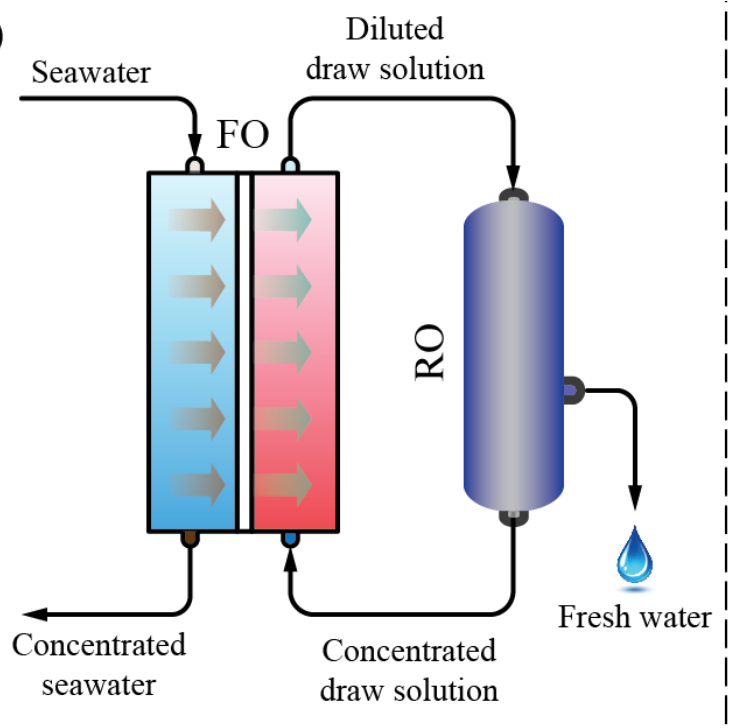

b)

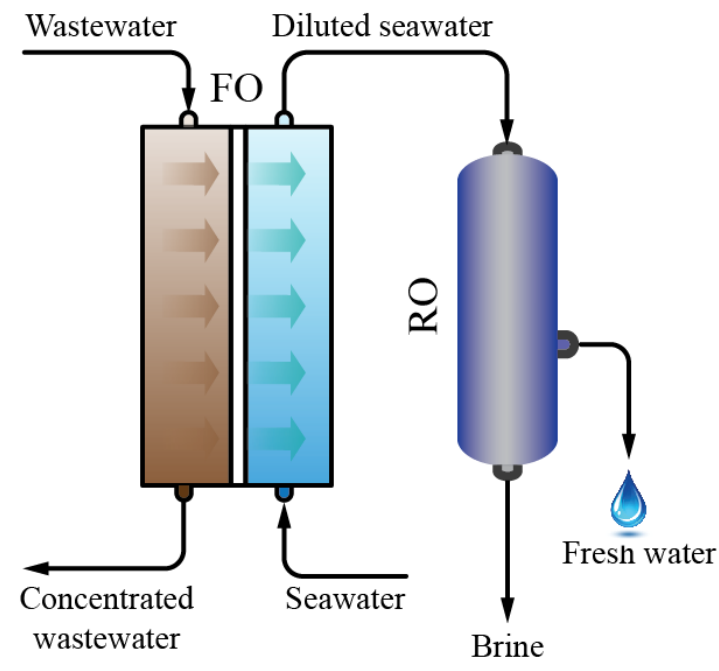

Fig. 3. FO-RO hybrid systems for (a) seawater desalination, and (b) simultaneous wastewater treatment and seawater desalination [33]. 
Another notable approach to improve the energy consumption of hybrid FO systems is to adopt draw solute regeneration processes that utilise thermal energy instead of electrical energy 230 [37]. For example, thermally responsive draw solutes such as ammonia carbon dioxide $231\left(\mathrm{NH}_{3} / \mathrm{CO}_{2}\right)$ are easily regenerated using low grade heat, by converting the ammonium salts into ammonia and carbon dioxide gas [38]. Pilot-scale demonstrations for shale gas produced water 233 using a $\mathrm{NH}_{3} / \mathrm{CO}_{2} \mathrm{FO}$ process had a specific thermal energy consumption of approximately 275 $234 \mathrm{kWh}_{\mathrm{th}} / \mathrm{m}^{3}$, which is significantly lower than the $633 \mathrm{kWh} \mathrm{h}_{\mathrm{th}} / \mathrm{m}^{3}$ required for conventional 235 evaporative desalination methods [39]. Similarly, combining FO with MD is another option to 236 achieve energy savings by utilising low grade heat or solar thermal energy sources. As discussed in the section 4, MD has exceptional salt rejection and is not limited by osmotic pressure, as compared with pressure driven processes. Because MD might be prone to fouling, FO can provide pre-treatment to reduce organic fouling and inorganic scaling in MD, as shown by successful demonstrations in treating challenging solutions such as municipal and dairy wastewater [40, 41], activated sludge [42] and landfill leachate [43]. It is noteworthy that the

242 benefits of FO in regard to treating high fouling potential and highly saline solutions cannot be accurately captured by energy analysis since these complex solutions are often incompatible with conventional desalination processes [26].

A related process with potential to complement low carbon desalination is pressure retarded osmosis (PRO). This emerging technology is based on the same principal as FO, however the salinity gradient energy is harvested via enclosing the draw solution and capturing the mechanical energy created by the increasing draw solution volume [44]. Hydro turbines or energy recovery devices are used to convert this mechanical energy to electricity to power a RO

250 desalination process. PRO feasibility strongly depends on the magnitude of available salinity 251 gradients since a number of energy inputs (i.e. pumping and pre-treatment) are required to effectively operate the process. Interest in incorporating PRO with RO desalination plants (Fig.

253 4) has shown theoretical reductions in energy consumption when impaired water sources are 254 available, however a number of practical considerations are yet to be addressed as discussed elsewhere [45]. 


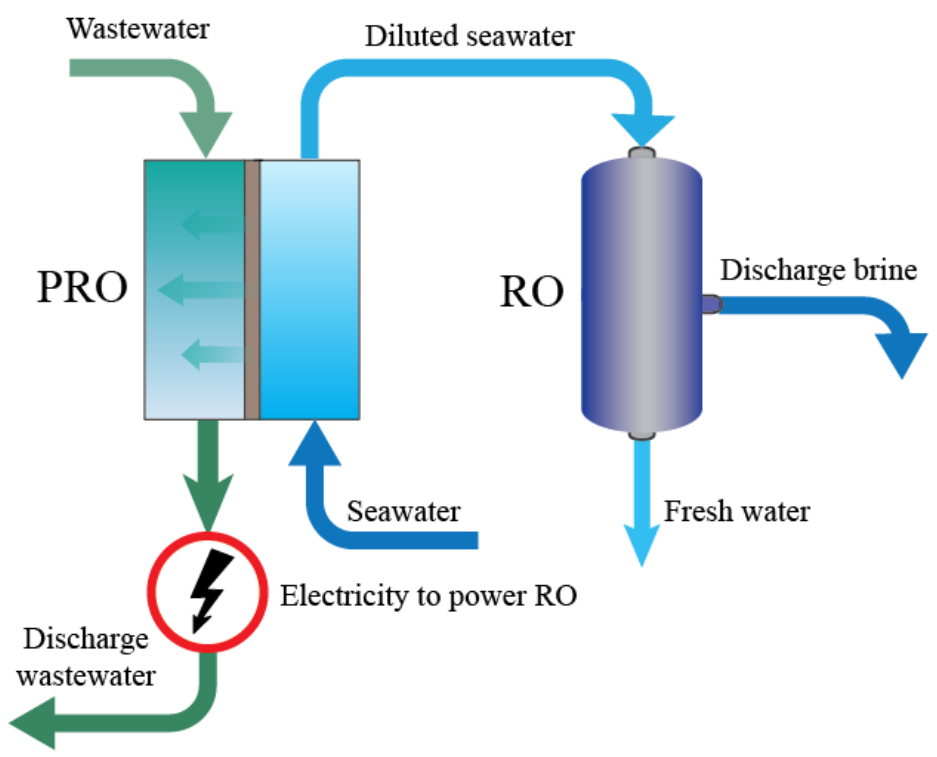

Fig. 4. Schematic diagram of an integrated PRO-RO process for low carbon desalination.

\section{Membrane distillation}

Membrane distillation (MD), a thermally driven membrane separation process, embodies several attributes ideal for low carbon desalination. The MD desalination process utilises a hydrophobic microporous membrane to separate a hot saline feed and a cold fresh distillate and the temperature difference between two sides of the membrane as the process driving force. Thermal energy is the primary energy input into the MD desalination process $[46,47]$, and the MD process can be efficiently operated at mild feed temperature (i.e. $40-80{ }^{\circ} \mathrm{C}$ ), allowing for the deployment of waste heat or solar thermal to power the process. Thus, where these lowgrade energy sources are available, MD can be an attractive energy-saving and low carbon desalination technology platform. Moreover, as a thermally driven separation method, the MD process is negligibly subject the osmotic pressure of the feed solution and hence compatible with highly saline solutions, extending its applications for desalination of brines from RO and other desalination processes. In addition, since the MD process does not involve a high

272 for intensive feed water pre-treatment like in RO.

MD configurations strongly affect the energy consumption of the process. In practice, MD can be operated in four basic configurations, including direct contact membrane distillation (DCMD), air gap membrane distillation (AGMD), vacuum membrane distillation (VMD), and sweeping gas membrane distillation (SGMD). Amongst these configurations, DCMD exhibits 
the lowest process thermal efficiency because the hot feed and the cold distillate streams are

278 separated by only a thin membrane in DCMD, leading to a noticeable conduction heat loss through the membrane. The deployment of vacuum and sweeping gas on the permeate side of the membrane in VMD and SGMD helps alleviate the conduction heat loss, and hence improving their thermal efficiency compared to DCMD. Similarly, in AGMD, an air gap is inserted between the feed and distillate streams to mitigate the conduction heat loss, and in tandem facilitate the recovery of the condensation latent heat. Thus, AGMD can achieve a much higher thermal efficiency than DCMD.

Many attempts have been made to improve thermal efficiency and to reduce the thermal energy consumption of the MD desalination process. A notable example is the combination of multi-effect with vacuum in a novel MD configuration termed vacuum-multi-effect MD (VMEMD), which has been commercialised by Memsys [48]. In this configuration, the feed water into a stage functions as the coolant to recover the condensation latent heat in the previous stage, and varying vacuum is applied in stages to increase water flux and reduce the conduction heat loss (Fig. 5). Thus, V-MEMD demonstrates a remarkably improved thermal efficiency compared to the basic MD configurations. A pilot V- MEMD could achieve thermal efficiency of $90 \%$ (i.e. equivalent to $10 \%$ heat loss) and a specific thermal energy consumption of 144.5 $\mathrm{kWh} / \mathrm{m}^{3}[49]$.

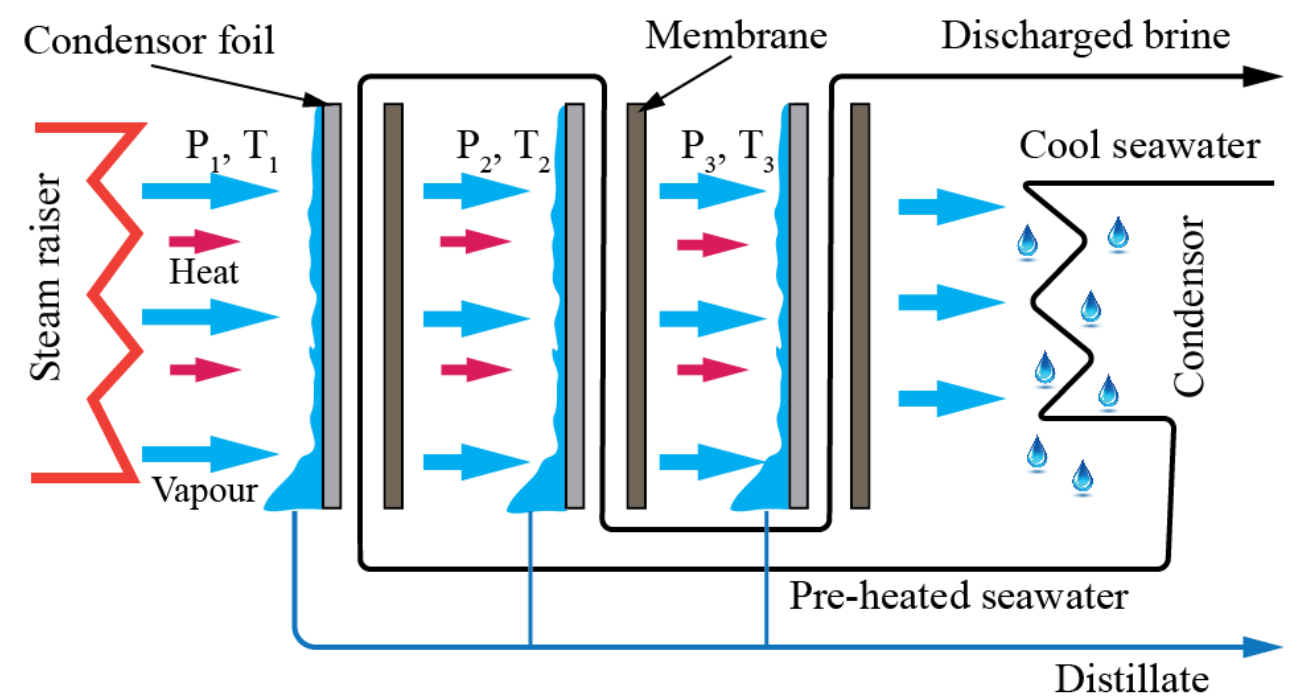

Distillate

Fig. 5. Recovery of condensation latent heat for improved energy efficiency in the seawater VMEMD desalination process (adapted from [48]).

The recovery of the condensation latent heat to reduce the process thermal energy consumption can be also obtained with the pilot or large-scale AGMD process. The saline feed 
water can be circulated through the coolant channel to act as a coolant (Fig. 6). Given the long coolant channel, the feed water is sufficiently preheated by the condensation latent heat. The preheated feed water then can be additionally heated by an external heat source to reach a desired temperature prior to entering the feed channel of the AGMD membrane module (Fig. 6). Duong et al. [47] optimised a pilot seawater AGMD process with internal latent heat recovery. The authors highlighted the importance of process optimisation to enhance energy efficiency and hence to reduce the specific energy consumption of the process. The feed inlet temperature and water circulation rate were critical operating parameters profoundly affecting the process distillate production and thermal efficiency. Operating the AGMD process at high feed inlet temperature and low water circulation rate was beneficial regarding to the process energy efficiency. At the optimum operating conditions, the AGMD process achieved specific thermal and electrical energy consumption of 90 and $0.13 \mathrm{kWh} / \mathrm{m}^{3}$, respectively [47].

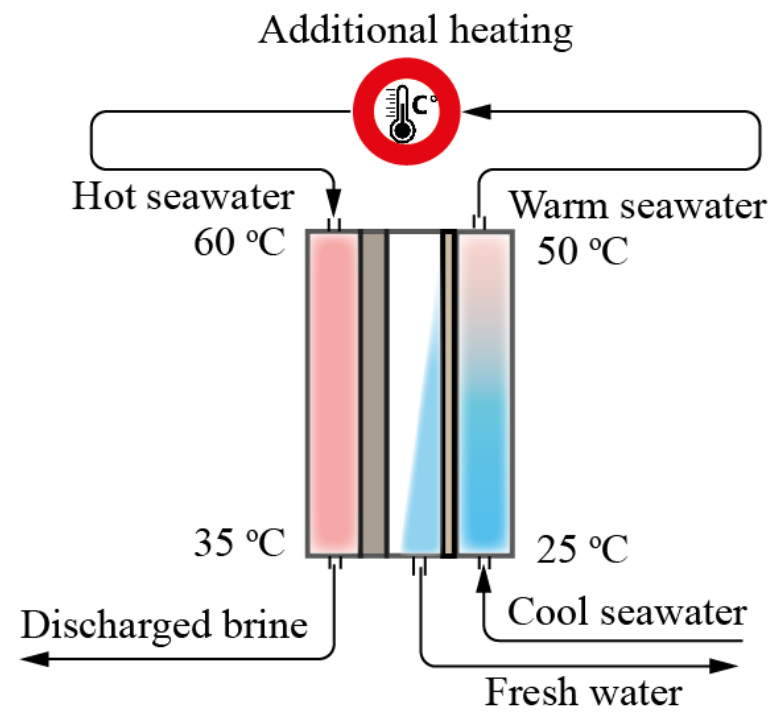

Fig. 6. A seawater AGMD desalination process with internal condensation latent heat recovery. Unlike in AGMD, the recovery of latent heat in DCMD can only be viable when using an external heat exchanger to recover latent heat accumulated in the distillate stream to preheat the feed stream [50]. In the DCMD process combined with an external heat exchanger, the process energy consumption is strongly influenced by the relative flow rate between the feed and the distillate streams and the surface areas of the heat exchanger and the membrane module. Lin et al. [50] reported that the DCMD process could obtain a minimum specific thermal energy consumption of $8 \mathrm{kWh} / \mathrm{m}^{3}$ with infinite heat exchanger and membrane module surfaces at a critical relative flow rate. However, it is worth noting that it is unpractical to use the DCMD process with infinite heat exchanger and membrane module surfaces. 
Another approach to reducing energy consumption of the DCMD process is to recover the sensible heat of the brine stream by brine recycling. In the DCMD process, particularly for the small-scale system with short membrane channels, the warm brine leaving the membrane module contains a considerable amount of sensible heat. Brine recycling enables the recovery of the brine sensible heat, thus leading to reduction in the process thermal energy consumption. Indeed, Duong et al. [51] demonstrated that recycling brine in a small-scale DCMD process helped reduce the process specific thermal energy consumption by more than half. Recycling brine also facilitated the utilisation of the membrane surface area to increase the process water recovery. Along with other operating parameters, the water recovery of the seawater DCMD desalination process with brine recycling determined the process energy consumption, and the optimal water recovery with respect to energy consumption was in the range from 20 to $60 \%$ [51].

Coupling MD with waste heat and renewable energy is a practical approach to low carbon desalination. The MD process powered by industrial waste heat and solar thermal energy has been successfully demonstrated for fresh water provision [49, 52-57]. A notable example can be the DCMD process supplied with waste heat from a gas fired power station to reclaim fresh water from saline demineralisation regeneration waste [53]. The process was trialled for over three months, and a high-quality distillate with total dissolved salts rejection of $99.9 \%$ was obtained [53]. A fully solar powered MD system was also deployed for potable water provision in arid remote areas [56]. The system mainly consisted of a V-MEMD membrane module, a solar-thermal collector, and a solar-PV panel. The engineered design of the system rendered it a portable, reliable, environmentally friendly, and sustainable desalination technology [56].

High resistance to membrane fouling is a noticeable advantage of MD for low carbon desalination applications. Most of the demonstrated MD processes for desalination applications involved a negligible feed water pre-treatment. Feed water to the MD process was either raw or pre-filtered (i.e. using paper filters or cartridge filters) seawater. When the MD process was operated at low water recoveries, membrane fouling was mostly not evident even for extended operation (i.e. for several months) $[53,54]$. Membrane scaling caused by the precipitation of inorganic sparingly soluble salts only occurred when the MD process was pushed beyond their saturation limits. The scale layers formed on the membrane surface limited the active membrane surface for water evaporation, aggravated the temperature and concentration polarisation effects, and altered the membrane surface hydrophobicity, thus reducing the process water flux and 
deteriorating the quality of the obtained distillate. However, the scale formation in the MD

356 process could be effectively controlled by regulating the process operating parameters [58] or rinsed out using non-toxic domestic cleaning agents [59]. The high resistance to membrane fouling and scaling actually enables the MD process for treatment of brines from other desalination processes such as RO, ED, FO, and CDI.

\section{Electrodialysis}

Electrodialysis (ED) is an electrically driven membrane separation process in which cation

362 exchange membranes (CEMs) and anion exchange membranes (AEMs) are used to facilitate

363 the selective transport of cations and anions through the membranes. In ED units, CEMs and 364 AEMs are placed alternatively between the anode and the cathode (Fig. 7). When an electric 365 field is applied, cations migrate through CEMs toward the anode, while anions move through 366 AEMs toward the cathode, leading to the depletion of salt concentration in the desalinated water and the salt enrichment in the brine.

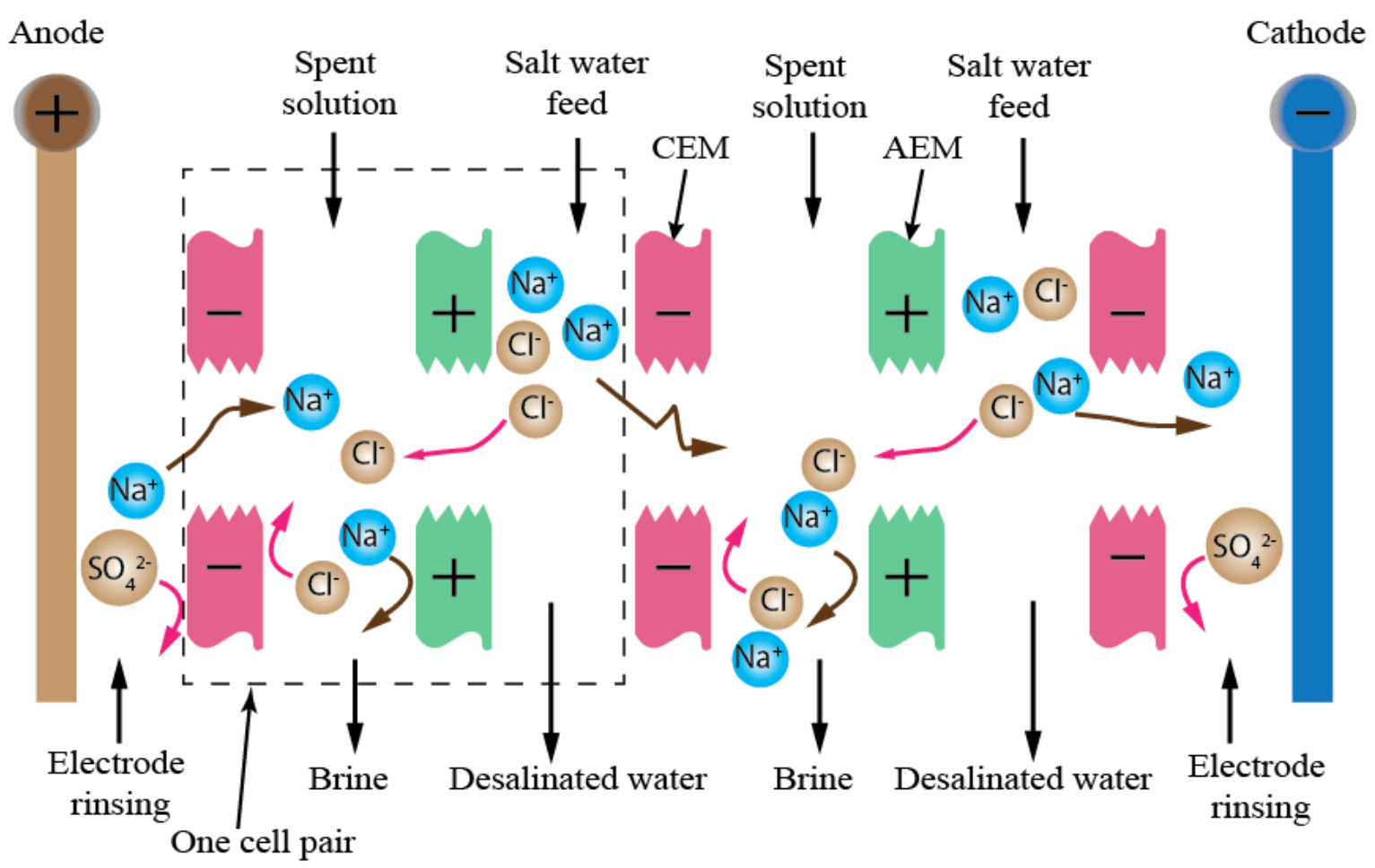

Fig. 7. Working principles of an ED process for desalination application. 
In the ED process, electricity is consumed to generate the electric field between the 371 electrodes and to drive pumps for water circulation. The electricity consumed by the electrodes $\left(P_{e l}\right)$ is the primary energy consumption of the ED process, and can be calculated as [60]:

374

$$
P_{e l}=n \Delta V I
$$

where $n$ is the number of ED cell pairs, $\Delta V$ is the voltage drop over the cell pair, and $I$ is the electric current. Thus, the specific energy consumption (SEC) of the ED desalination process can be expressed as [60]:

$$
S E C=\frac{n \Delta V I}{Q_{D}}
$$

where $Q_{D}$ is the dilute flow rate $\left(\mathrm{m}^{3}\right)$. The voltage drop over the cell pair is expressed as:

$$
\Delta V=\eta_{\text {non-Ohm }}+r_{\text {Ohm }} I
$$

where $\eta_{n o n-O h m}$ is the non-Ohmic voltage drop and $r_{\text {Ohm }}$ is the overall Ohmic resistance of the cell pair. The non-Ohmic voltage drop depends on salt concentrations and the hydrodynamics of the concentrate and the dilute compartments, and it becomes significant when the salt concentration gradient between the concentrate and the dilute compartments increases. The overall Ohmic resistance is composed of membrane resistances and the resistances of the dilute and concentrate compartments. It has been proved that overall Ohmic resistance is inversely proportional to the salt concentrations in the dilute and concentrate departments [60].

For the ED desalination process, the dilute flow rate is dependent on the transport rate of ions through the ion exchange membranes. A higher dilute flow rate can be achieved with an elevated ions transport rate. The flux of an ion $\left(J_{i}\right)$ through the ED membranes can be expressed as [60]:

$$
\overrightarrow{J_{i}}=-D_{i} \vec{\nabla} C_{i}+\frac{t_{i} \vec{i}}{z_{i} F}
$$


392

393

394

395

396

397

398

399

400

401

402

403

404

405

406

407

408

409

410

411

412

413

414

415

416

417

418

419

420

421

422

where $D$ is the electrolyte diffusion coefficient of the ion, $\nabla C_{i}$ is the ion concentration gradient, $t_{i}$ is the migration transport number, $i$ is the current density, $z_{i}$ is the valence of the ion, and $F$ is Faraday's constant.

Eqs. (1-4) demonstrate a profound influence of the feed water salinity on the specific energy consumption of the ED process. Increasing feed salinity results in not only a higher salt concentration gradient between the dilute and the concentrate compartments $\left(\nabla C_{i}\right)$ but also a decreased current density $(i)$ due to the concentration polarisation effect, hindering the transport of ions through the membranes. Increasing feed salinity also magnifies the non-Ohmic voltage drop over the cell pair $\left(\eta_{\text {non-Ohm }}\right)$, hence raising the energy consumption of the ED process. For low salinity desalination applications, the ED process is more energy efficient than RO. Indeed, an ED process with feed water salinity $\leq 2500 \mathrm{ppm}$ exhibits a specific energy consumption from 0.7 to $2.5 \mathrm{kWh} / \mathrm{m}^{3}[6,23]$. However, the energy consumption of the ED process considerably exceeds that of RO when treating feed waters with salinity above $5000 \mathrm{ppm}$. As a result, ED is largely applied for desalination of brackish water with limited salinity $[6,60]$.

Membrane fouling is another issue that affects the energy consumption of the ED process for desalination applications [60-62]. There is a consensus that ED is less subject to membrane fouling than RO; however, membrane fouling is still considered one of the limiting factors of the ED desalination process [60]. In the ED process, under the electric field, negatively charged colloidal particles ubiquitous in seawater or brackish are pushed toward the anode. The ion exchange membranes act as barriers and stop the colloidal particles migration, leading to the deposition of colloids on the membrane surface. The deposited colloids layers reduce membrane ion selectivity but increase membrane resistance and the pressure drop along the compartments, thus significantly increasing the energy consumption of the ED process. Sparingly soluble salts (e.g. $\mathrm{CaCO}_{3}$ and $\mathrm{CaSO}_{4}$ ) in seawater or brackish water also pose a risk of membrane scaling, particularly for the ED process operated at a high recovery rate. Common methods to prevent membrane fouling and scaling include feed water pre-treatment using MF and UF, $\mathrm{pH}$ adjustment, reduction of recovery rate, and membrane cleaning [60]. It is worth noting that applying these methods inevitably results in an increased in the energy consumption of the ED process.

Attempts to mitigate membrane fouling propensity and hence the energy consumption of the ED process focus on membrane surface modification and process optimisation. Notable 
examples for the membrane surface modification approach include the studies of Mulyati et al. [61] and Vaselbehagh et al. [62]. In these studies, the AEMs surface was modified by adding high molecular mass surfactants (e.g. poly sodium 4-styrene sulfonate and polydopamine) to enhance the negative surface charge density, hydrophilicity, and roughness of the AEMs. The surface-modified AEMs exhibited a higher antifouling potential and an increased membrane stability compared to the pristine ones.

The development of the electrodialysis reversal (EDR) concept made a breakthrough in membrane fouling mitigation and energy consumption reduction of the ED desalination process $[60,63]$. During an EDR desalination operation, the polarity of the electrodes and the diluate and concentrate channels are regularly reversed to facilitate the periodic removal of colloids and organic matter from the membrane surfaces. The foulants detached from the membrane surfaces are subsequently rinsed out of the ED cells by the flowing solutions. Given this selfcleaning mechanism, the EDR process exhibits a significantly reduced membrane fouling tendency compared to the ED process. The EDR concept also helps minimise feed water pretreatment and membrane cleaning procedures, obviating the need for additional equipment such as acids tanks, complexing agent tanks, dosing pumps and $\mathrm{pH}$ controllers [60]. Thus, the EDR concept leads to a significant reduction in the energy consumption of the ED desalination process.

\section{Capacitive deionisation}

The capacitive deionisation (CDI) process purifies water using the electrostatic adsorption and desorption capacity of conductive porous electrodes. The CDI desalination process involves two alternate steps: purification of salt water and regeneration of the electrodes (Fig. 8) [64-66]. During the purification step, as salt water travels along the CDI cell, ions or charged molecules migrate toward and subsequently are adsorbed by the oppositely charged electrodes, leading to the depletion of salt concentrations in the salt water feed and the attainment of desalinated water. During the electrodes regeneration step, the polarity of the electrodes is reversed, and the charged ions and molecules that have been attached to the electrodes in the purification step are desorbed from the electrodes and migrate back to the salt water. Thus, the adsorption capacity of the electrodes is regenerated, and a brine stream is produced at the outlet of the CDI cell. 


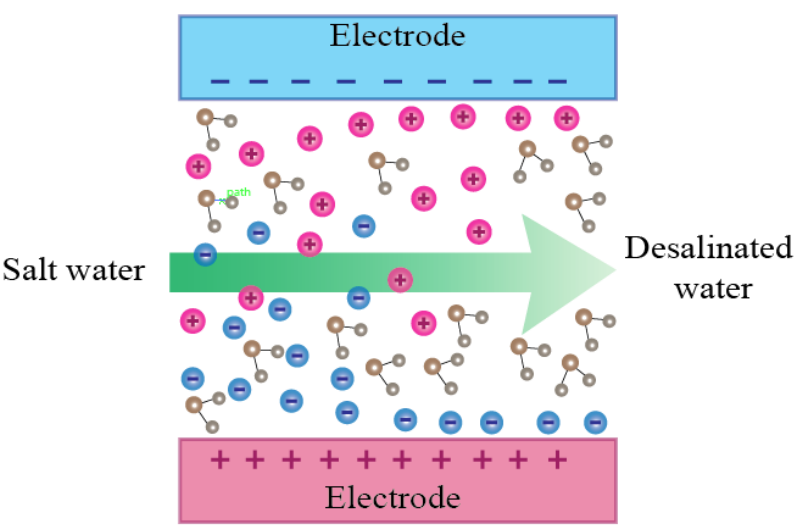

Purification

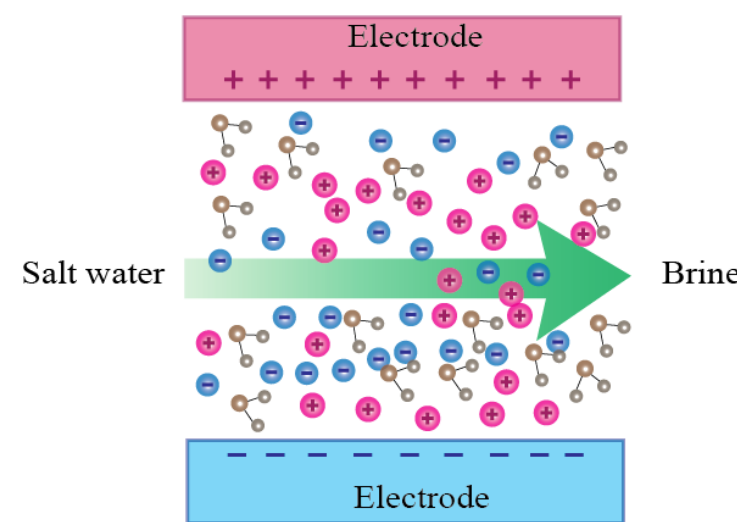

Regeneration

Fig. 8. Purification and regeneration steps in the CDI process (adapted from [64]).

CDI has emerged as a promising process for low carbon desalination applications. The CDI desalination process is operated at a limited electrical voltage (i.e. $<2 \mathrm{~V})$ and a low hydrostatic pressure $[64,65,67]$. It does not require high pressure pumps and costly tubing materials (i.e. stainless steel) like in the RO desalination process. The mild operation conditions also render the CDI desalination process significantly less prone to fouling, thus obviating the need for intensive feed water pre-treatment and regular membrane cleaning as required by the RO process $[64,68]$. The low-voltage operation also facilitates the coupling of CDI desalination with renewable energy sources (e.g. solar and wind energy) [67, 69]. More importantly, a large portion of the energy used for charging the electrodes during the purification step can be recovered in the electrode regeneration step $[70,71]$, thus significantly reducing the total energy demand and hence the carbon footprint of the CDI desalination process.

Like in ED, the desalination efficiency and energy consumption of the CDI process strongly depend on the process operating conditions, particularly the feed water salinity [64]. Increasing feed salinity results in an increase in the adsorption rate of ions to the electrodes but a reduction in the ions removal efficiency of the CDI cell. To achieve a desired effluent salinity, a longer adsorption interval or a higher electric current is required for more concentrated feed water, thus increasing the specific energy consumption of the CDI process. Indeed, Porada et al. [72] compared the specific energy consumption of the CDI and RO process and confirmed that CDI was only competitive to RO with respect to energy consumption for feed water with salinity approximately below 2000 ppm, which is the salinity of brackish water. Thus, similarly to ED, the CDI process is considered best suited for the desalination applications of brackish water [64, $67,72]$. 
The electrodes exert profound influences on the desalination efficiency and the energy consumption of the CDI process. The CDI desalination mechanism is governed by electrostatic adsorption of ions to the electrodes when they are in direct contact with salt water, and electrostatic adsorption is the driving force for the transfer of ions. As a result, electrostatic adsorption is the limiting factor of the CDI desalination process [64, 73, 74]. Key properties of the CDI electrodes include specific surface area, median pore diameter, total pore volume, resistance, and particularly specific capacitance. The specific capacitance, measured in F/g, is the amount of electrical charges (in coulomb) that can be stored by one mass unit of the electrode material under an electric potential of 1 volt. Thus, it is an indicator of the electrostatic adsorption capacity of the electrode.

Considerable efforts have been devoted to exploring suitable electrodes for improved ions separation and energy efficiency of the CDI process. The most commonly used CDI electrodes are prepared from activated carbons with poly vinylidene fluoride used as a binder. Given the high porosity and rich carbon content of activated carbons, the activate carbon electrodes possess excellent specific surface areas (i.e. above $2000 \mathrm{~m}^{2} / \mathrm{g}$ ), micro-pore structure with pore sizes ranging from 1.0 to $2.5 \mathrm{~nm}$ and a total pore volume of 0.57 to $1.63 \mathrm{~cm}^{3} / \mathrm{g}$, and specific capacitance of 60 to $125 \mathrm{~F} / \mathrm{g}$ [75]. The hydrophobic nature of activated carbons is a drawback of activated carbon electrodes. It repels water solution from the activated carbon electrodes and hinders the direct contact between the electrodes and the solution, thus negatively affecting the adsorption capacity of the electrodes [64]. Novel materials such as carbide derived carbons, carbon aerogel, carbon nanotubes (CNTs) and carbon nanofibers (CNFs), graphene, and mesoporous carbons have also been proposed and demonstrated for the CDI desalination process. Porada et al. [72, 76] reported an adsorption capacity increase by $28-44 \%$ for the electrodes prepared from carbide derived carbons compared to those prepared by activated carbons. The increased adsorption capacity of the carbide derived carbons electrodes was attributed to the super specific surface area and the pore size tunability in the sub-nanometer range of the carbide derived carbons material [76]. Similarly, electrodes prepared from carbon aerogel exhibited high specific surface area, controllable pore size distribution, and superior electrical properties; therefore, they were selected for many CDI desalination processes [77]. Nano carbon materials such as CNTs, CNFs, and graphene have recently emerged as promising materials for CDI electrodes. Given their nano-structures, electrodes prepared from CNTs, CNFs, and graphene have specific surface areas considerably higher than those offered by the 
activated carbons electrodes. CNTs, CNFs, and graphene also exhibit superior conductivity to activated carbons [78-80]. Thus, the advancement in CNTs, CNF, and graphene materials promises to improve the ions separation and energy efficiency of the CDI desalination process.

Process modification is an alternative approach to improving desalination and energy efficiency of the CDI process. Indeed, the CDI process suffers a serious problem during the regeneration of the electrodes [64]. When the polarity of the electrodes is reversed to desorb the 514 charged ions that have been adsorbed during the purification step, the oppositely charged ions 515 from the bulk solution are attracted and adsorbed to the electrodes (Fig. 8). Thus, the electrode 516 regeneration involves simultaneous desorption and adsorption of charged ions from and to the 517 electrodes, reducing the adsorption capacity of the electrodes in the subsequent purification step and hence negatively affecting the desalination and energy efficiency of the CDI process. To address this issue, ion-exchange membranes are introduced to the CDI cells (Fig. 9). Like in the ED process, ion-exchange membranes selectively allow the permeation of cations or anions; therefore, the adsorption of the oppositely charged ions during the electrode regeneration step is effectively prevented (Fig. 9). Given the usage of ion-exchange membranes, the modified CDI process is termed membrane capacitive deionisation (MCDI). Experimental demonstrations of the MCDI process have confirmed that MCDI is clearly preferable to CDI regarding the process salt removal and energy recovery [73, 74, 81, 82]. Indeed, depending on the process operating conditions, the MCDI process can achieve a salt removal and energy recovery of $49 \%$ and $34 \%$, respectively, higher than that of the CDI process [70, 83].

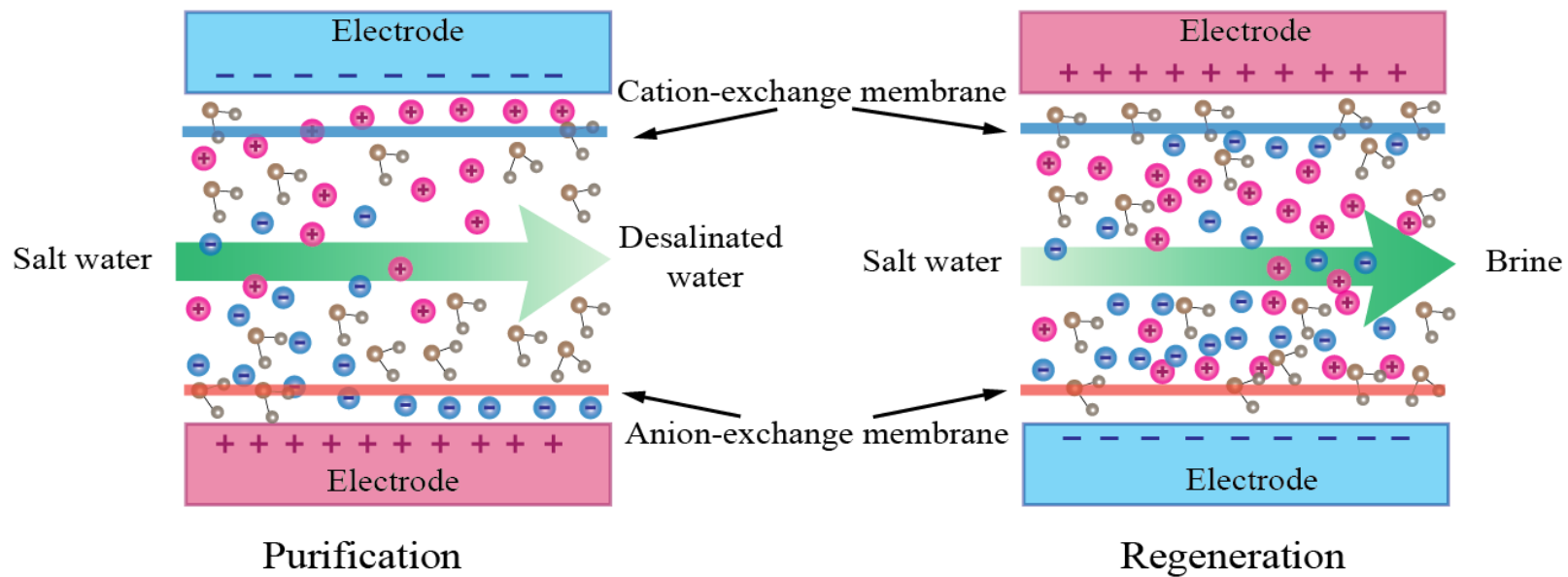

Fig. 9. Purification and regeneration steps in the MCDI process (adapted from [64]). 


\section{Conclusions}

531 As a mature desalination process, RO is deemed a benchmark for other emerging 532 membrane-based desalination processes. The energy consumption of seawater RO has been 533 remarkedly reduced given enormous advances in membrane materials and energy recovery 534 devices. The exploration of ultra-permeable membranes using innovative materials such as 535 Aquaporin, carbon nanotubes, and graphene promises to further reduce the energy consumption 536 of the RO desalination process. Particularly, RO desalination energy consumption can approach 537 the minimum desalination energy demand by multi-staging the process but with an increase in 538 investment and operational costs. As an osmotically driven separation methods, FO can be a 539 favourable low carbon desalination process when it is used as a standalone process whereby the 540 regeneration of FO draw solutions is obviated. The ED and CDI processes offer energy-efficient 541 and low carbon desalination means; nevertheless, they are only effective and competitive to RO 542 for desalination of saline waters with low salinity (i.e. brackish water). In addition, further 543 intensive works are required on improvement of ion-exchange membranes and electrodes and 544 process optimisation prior to the commercial realisation of ED and CDI for low carbon 545 desalination applications. Finally, the emerging thermally driven MD process currently exhibits 546 energy consumption higher than that of RO and FO; however, MD can be coupled with waste 547 heat and solar thermal energy and compatible with hyper saline solutions that are beyond the

548 limits of RO and FO. MD can be deployed as a complementary process for RO and FO or as 549 standalone process exploiting low-grade heat sources. Thus, MD can be the most promising 550 energy-saving alternative to RO for low carbon desalination.

\section{Conflict of interest statement}

552 On behalf of all authors, the corresponding author states that there is no conflict of interest.

\section{References}

1. M. Elimelech and W.A. Phillip, The Future of Seawater Desalination: Energy, Technology, and the Environment, Science 333 (2011) 712-717.

556 2. International Desalination Association, Desalination by the numbers, 2015, [Online] Available: http://idadesal.org/desalination-101/desalination-by-the-numbers/.

558 3. V.G. Gude, Desalination and sustainability - An appraisal and current perspective, Water 559 Research 89 (2016) 87-106. 
4. A.G. Fane, A grand challenge for membrane desalination: More water, less carbon, Desalination 426 (2018) 155-163.

5. H. Shemer and R. Semiat, Sustainable RO desalination - Energy demand and environmental impact, Desalination 424 (2017) 10-16.

6. A. Al-Karaghouli and L.L. Kazmerski, Energy consumption and water production cost of conventional and renewable-energy-powered desalination processes, Renewable and Sustainable Energy Reviews 24 (2013) 343-356.

7. J. Liu, S. Chen, H. Wang, and X. Chen, Calculation of Carbon Footprints for Water Diversion and Desalination Projects, Energy Procedia 75 (2015) 2483-2494.

8. Christiana Figueres, Hans Joachim Schellnhuber, Gail Whiteman, Johan Rockström, Anthony Hobley, and S. Rahmstorf, Three years to safeguard our climate, Nature 546 (2017) 593-595.

9. G.K. Pearce, UF/MF pre-treatment to RO in seawater and wastewater reuse applications: a comparison of energy costs, Desalination 222 (2008) 66-73.

10. D. Cohen-Tanugi, R.K. McGovern, S.H. Dave, J.H. Lienhard, and J.C. Grossman, Quantifying the potential of ultra-permeable membranes for water desalination, Energy \& Environmental Science 7 (2014) 1134-1141.

11. X. Li, S. Chou, R. Wang, L. Shi, W. Fang, G. Chaitra, C.Y. Tang, J. Torres, X. Hu, and A.G. Fane, Nature gives the best solution for desalination: Aquaporin-based hollow fiber composite membrane with superior performance, Journal of Membrane Science 494 (2015) 68-77.

12. P.S. Goh, A.F. Ismail, and B.C. Ng, Carbon nanotubes for desalination: Performance evaluation and current hurdles, Desalination 308 (2013) 2-14.

13. D. Cohen-Tanugi and J.C. Grossman, Water Desalination across Nanoporous Graphene, Nano Letters 12 (2012) 3602-3608.

14. A. Zhu, P.D. Christofides, and Y. Cohen, Effect of Thermodynamic Restriction on Energy Cost Optimization of RO Membrane Water Desalination, Industrial \& Engineering Chemistry Research 48 (2009) 6010-6021.

15. S. Lin and M. Elimelech, Staged reverse osmosis operation: Configurations, energy efficiency, and application potential, Desalination 366 (2015) 9-14.

16. D.M. Warsinger, E.W. Tow, K.G. Nayar, L.A. Maswadeh, and J.H. Lienhard V, Energy efficiency of batch and semi-batch (CCRO) reverse osmosis desalination, Water Research 106 (2016) 272-282.

17. A. Efraty, R.N. Barak, and Z. Gal, Closed circuit desalination - A new low energy high recovery technology without energy recovery, Desalination and Water Treatment 31 (2011) 95-101.

18. T.M. Missimer, N. Ghaffour, A.H.A. Dehwah, R. Rachman, R.G. Maliva, and G. Amy, Subsurface intakes for seawater reverse osmosis facilities: Capacity limitation, water quality improvement, and economics, Desalination 322 (2013) 37-51.

19. B. Wu, S.R. Suwarno, H.S. Tan, L.H. Kim, F. Hochstrasser, T.H. Chong, M. Burkhardt, W. Pronk, and A.G. Fane, Gravity-driven microfiltration pretreatment for reverse osmosis (RO) seawater desalination: Microbial community characterization and RO performance, Desalination 418 (2017) 1-8. 
20. B. Wu, F. Hochstrasser, E. Akhondi, N. Ambauen, L. Tschirren, M. Burkhardt, A.G. Fane, and W. Pronk, Optimization of gravity-driven membrane (GDM) filtration process for seawater pretreatment, Water Research 93 (2016) 133-140.

21. E. Akhondi, B. Wu, S. Sun, B. Marxer, W. Lim, J. Gu, L. Liu, M. Burkhardt, D. McDougald, W. Pronk, and A.G. Fane, Gravity-driven membrane filtration as pretreatment for seawater reverse osmosis: Linking biofouling layer morphology with flux stabilization, Water Research 70 (2015) 158-173.

22. D. Zarzo and D. Prats, Desalination and energy consumption. What can we expect in the near future?, Desalination 427 (2018) 1-9.

23. N. Voutchkov, Energy use for membrane seawater desalination - current status and trends, Desalination 431 (2018) 2-14.

24. A. Subramani, M. Badruzzaman, J. Oppenheimer, and J.G. Jacangelo, Energy minimization strategies and renewable energy utilization for desalination: A review, Water Research 45 (2011) 1907-1920.

25. R. Mcginnis and A. Mandell, Utility scale osmotic grid storage, O.W. Inc., Editor. 2011.

26. D.L. Shaffer, J.R. Werber, H. Jaramillo, S. Lin, and M. Elimelech, Forward osmosis: Where are we now?, Desalination 356 (2015) 271-284.

27. S. Zou, H. Yuan, A. Childress, and Z. He, Energy Consumption by Recirculation: A Missing Parameter When Evaluating Forward Osmosis, Environmental Science \& Technology 50 (2016) 6827-6829.

28. S. Phuntsho, J.E. Kim, S. Hong, N. Ghaffour, T. Leiknes, J.Y. Choi, and H.K. Shon, A closed-loop forward osmosis-nanofiltration hybrid system: Understanding process implications through full-scale simulation, Desalination 421 (2017) 169-178.

29. E. Butler, A. Silva, K. Horton, Z. Rom, M. Chwatko, A. Havasov, and J.R. McCutcheon, Point of use water treatment with forward osmosis for emergency relief, Desalination 312 (2013) 23-30.

30. Y.-N. Wang, K. Goh, X. Li, L. Setiawan, and R. Wang, Membranes and processes for forward osmosis-based desalination: Recent advances and future prospects, Desalination 434 (2018) 81-99.

31. J.E. Kim, S. Phuntsho, L. Chekli, S. Hong, N. Ghaffour, T. Leiknes, J.Y. Choi, and H.K. Shon, Environmental and economic impacts of fertilizer drawn forward osmosis and nanofiltration hybrid system, Desalination 416 (2017) 76-85.

32. Su-bin Kim, Sachin Paudel, and G.T. Seo, Forward osmosis membrane filtration for microalgae harvesting cultivated in sewage effluent., Environmental Engineering Research 20 (2015) 99-104.

33. R. Valladares Linares, Z. Li, S. Sarp, S.S. Bucs, G. Amy, and J.S. Vrouwenvelder, Forward osmosis niches in seawater desalination and wastewater reuse, Water Research 66 (2014) 122-139.

34. C.F. Wan and T.-S. Chung, Techno-economic evaluation of various RO+PRO and RO+FO integrated processes, Applied Energy 212 (2018) 1038-1050.

35. R. Valladares Linares, Z. Li, V. Yangali-Quintanilla, N. Ghaffour, G. Amy, T. Leiknes, and J.S. Vrouwenvelder, Life cycle cost of a hybrid forward osmosis - low pressure reverse 
osmosis system for seawater desalination and wastewater recovery, Water Research 88 (2016) 225-234.

36. V. Yangali-Quintanilla, Z. Li, R. Valladares, Q. Li, and G. Amy, Indirect desalination of Red Sea water with forward osmosis and low pressure reverse osmosis for water reuse, Desalination 280 (2011) 160-166.

37. Y. Cai and X.M. Hu, A critical review on draw solutes development for forward osmosis, Desalination 391 (2016) 16-29.

38. J.R. McCutcheon, R.L. McGinnis, and M. Elimelech, A novel ammonia-carbon dioxide forward (direct) osmosis desalination process, Desalination 174 (2005) 1-11.

39. R.L. McGinnis, N.T. Hancock, M.S. Nowosielski-Slepowron, and G.D. McGurgan, Pilot demonstration of the $\mathrm{NH}_{3} / \mathrm{CO}_{2}$ forward osmosis desalination process on high salinity brines, Desalination 312 (2013) 67-74.

40. M. Xie, L.D. Nghiem, W.E. Price, and M. Elimelech, A Forward Osmosis-Membrane Distillation Hybrid Process for Direct Sewer Mining: System Performance and Limitations, Environmental Science \& Technology 47 (2013) 13486-13493.

41. H. Song, F. Xie, W. Chen, and J. Liu, FO/MD hybrid system for real dairy wastewater recycling, Environmental Technology (2017) 1-11.

42. W. Luo, H.V. Phan, G. Li, F.I. Hai, W.E. Price, M. Elimelech, and L.D. Nghiem, An Osmotic Membrane Bioreactor-Membrane Distillation System for Simultaneous Wastewater Reuse and Seawater Desalination: Performance and Implications, Environmental Science \& Technology 51 (2017) 14311-14320.

43. Y. Zhou, M. Huang, Q. Deng, and T. Cai, Combination and performance of forward osmosis and membrane distillation (FO-MD) for treatment of high salinity landfill leachate, Desalination 420 (2017) 99-105.

44. T.Y. Cath, A.E. Childress, and M. Elimelech, Forward osmosis: Principles, applications, and recent developments, Journal of Membrane Science 281 (2006) 70-87.

45. A.P. Straub, A. Deshmukh, and M. Elimelech, Pressure-retarded osmosis for power generation from salinity gradients: is it viable?, Energy \& Environmental Science 9 (2016) 31-48.

46. H.C. Duong, P. Cooper, B. Nelemans, T.Y. Cath, and L.D. Nghiem, Evaluating energy consumption of membrane distillation for seawater desalination using a pilot air gap system, Separation and Purification Technology 166 (2016) 55-62.

47. H.C. Duong, A.R. Chivas, B. Nelemans, M. Duke, S. Gray, T.Y. Cath, and L.D. Nghiem, Treatment of RO brine from CSG produced water by spiral-wound air gap membrane distillation - A pilot study, Desalination 366 (2015) 121-129.

48. K. Zhao, W. Heinzl, M. Wenzel, S. Büttner, F. Bollen, G. Lange, S. Heinzl, and N. Sarda, Experimental study of the memsys vacuum-multi-effect-membrane-distillation (VMEMD) module, Desalination 323 (2013) 150-160.

49. A.E. Jansen, J.W. Assink, J.H. Hanemaaijer, J. van Medevoort, and E. van Sonsbeek, Development and pilot testing of full-scale membrane distillation modules for deployment of waste heat, Desalination 323 (2013) 55-65. 
50. S. Lin, N.Y. Yip, and M. Elimelech, Direct contact membrane distillation with heat recovery: Thermodynamic insights from module scale modeling, Journal of Membrane Science 453 (2014) 498-515.

51. H.C. Duong, P. Cooper, B. Nelemans, and L.D. Nghiem, Optimising thermal efficiency of direct contact membrane distillation via brine recycling for small-scale seawater desalination, Desalination 374 (2015) 1-9.

52. G. Zaragoza, A. Ruiz-Aguirre, and E. Guillén-Burrieza, Efficiency in the use of solar thermal energy of small membrane desalination systems for decentralized water production, Applied Energy 130 (2014) 491-499.

53. N. Dow, S. Gray, J.-d. Li, J. Zhang, E. Ostarcevic, A. Liubinas, P. Atherton, G. Roeszler, A. Gibbs, and M. Duke, Pilot trial of membrane distillation driven by low grade waste heat: Membrane fouling and energy assessment, Desalination (2016).

54. W.G. Shim, K. He, S. Gray, and I.S. Moon, Solar energy assisted direct contact membrane distillation (DCMD) process for seawater desalination, Separation and Purification Technology 143 (2015) 94-104.

55. Y.-D. Kim, K. Thu, and S.-H. Choi, Solar-assisted multi-stage vacuum membrane distillation system with heat recovery unit, Desalination 367 (2015) 161-171.

56. A. Chafidz, S. Al-Zahrani, M.N. Al-Otaibi, C.F. Hoong, T.F. Lai, and M. Prabu, Portable and integrated solar-driven desalination system using membrane distillation for arid remote areas in Saudi Arabia, Desalination 345 (2014) 36-49.

57. R. Schwantes, A. Cipollina, F. Gross, J. Koschikowski, D. Pfeifle, M. Rolletschek, and V. Subiela, Membrane distillation: Solar and waste heat driven demonstration plants for desalination, Desalination 323 (2013) 93-106.

58. H.C. Duong, M. Duke, S. Gray, T.Y. Cath, and L.D. Nghiem, Scaling control during membrane distillation of coal seam gas reverse osmosis brine, Journal of Membrane Science 493 (2015) 673-682.

59. H.C. Duong, M. Duke, S. Gray, P. Cooper, and L.D. Nghiem, Membrane scaling and prevention techniques during seawater desalination by air gap membrane distillation, Desalination 397 (2016) 92-100.

60. A. Campione, L. Gurreri, M. Ciofalo, G. Micale, A. Tamburini, and A. Cipollina, Electrodialysis for water desalination: A critical assessment of recent developments on process fundamentals, models and applications, Desalination 434 (2018) 121-160.

61. S. Mulyati, R. Takagi, A. Fujii, Y. Ohmukai, T. Maruyama, and H. Matsuyama, Improvement of the antifouling potential of an anion exchange membrane by surface modification with a polyelectrolyte for an electrodialysis process, Journal of Membrane Science 417-418 (2012) 137-143.

62. M. Vaselbehagh, H. Karkhanechi, S. Mulyati, R. Takagi, and H. Matsuyama, Improved antifouling of anion-exchange membrane by polydopamine coating in electrodialysis process, Desalination 332 (2014) 126-133.

63. M. Turek, P. Dydo, and J. Waś, Electrodialysis reversal in high CaSO4 supersaturation mode, Desalination 198 (2006) 288-294.

64. F.A. AlMarzooqi, A.A. Al Ghaferi, I. Saadat, and N. Hilal, Application of Capacitive Deionisation in water desalination: A review, Desalination 342 (2014) 3-15. 
65. P. Dorji, J. Choi, D.I. Kim, S. Phuntsho, S. Hong, and H.K. Shon, Membrane capacitive deionisation as an alternative to the 2 nd pass for seawater reverse osmosis desalination plant for bromide removal, Desalination 433 (2018) 113-119.

66. C.C. Hu, C.F. Hsieh, Y.J. Chen, and C.F. Liu, How to achieve the optimal performance of capacitive deionization and inverted-capacitive deionization, Desalination 442 (2018) 8998.

67. W. Zhang, M. Mossad, and L. Zou, A study of the long-term operation of capacitive deionisation in inland brackish water desalination, Desalination 320 (2013) 80-85.

68. M. Mossad and L. Zou, Study of fouling and scaling in capacitive deionisation by using dissolved organic and inorganic salts, Journal of Hazardous Materials 244-245 (2013) 387393.

69. M.A. Anderson, A.L. Cudero, and J. Palma, Capacitive deionization as an electrochemical means of saving energy and delivering clean water. Comparison to present desalination practices: Will it compete?, Electrochimica Acta 55 (2010) 3845-3856.

70. P. Długołęcki and A. van der Wal, Energy Recovery in Membrane Capacitive Deionization, Environmental Science \& Technology 47 (2013) 4904-4910.

71. J. Kang, T. Kim, H. Shin, J. Lee, J.-I. Ha, and J. Yoon, Direct energy recovery system for membrane capacitive deionization, Desalination 398 (2016) 144-150.

72. S. Porada, R. Zhao, A. van der Wal, V. Presser, and P.M. Biesheuvel, Review on the science and technology of water desalination by capacitive deionization, Progress in Materials Science 58 (2013) 1388-1442.

73. Y.J. Kim and J.H. Choi, Improvement of desalination efficiency in capacitive deionization using a carbon electrode coated with an ion-exchange polymer, Water Research 44 (2010) 990-996.

74. Y.J. Kim and J.H. Choi, Enhanced desalination efficiency in capacitive deionization with an ion-selective membrane, Separation and Purification Technology 71 (2010) 70-75.

75. J. Gamby, P.L. Taberna, P. Simon, J.F. Fauvarque, and M. Chesneau, Studies and characterisations of various activated carbons used for carbon/carbon supercapacitors, Journal of Power Sources 101 (2001) 109-116.

76. S. Porada, L. Weinstein, R. Dash, A. van der Wal, M. Bryjak, Y. Gogotsi, and P.M. Biesheuvel, Water Desalination Using Capacitive Deionization with Microporous Carbon Electrodes, ACS Applied Materials \& Interfaces 4 (2012) 1194-1199.

77. C.H. Hou, C.Y. Huang, and C.Y. Hu, Application of capacitive deionization technology to the removal of sodium chloride from aqueous solutions, International Journal of Environmental Science and Technology 10 (2013) 753-760.

78. J. Yang, L. Zou, and N.R. Choudhury, Ion-selective carbon nanotube electrodes in capacitive deionisation, Electrochimica Acta 91 (2013) 11-19.

79. Z. Wang, B. Dou, L. Zheng, G. Zhang, Z. Liu, and Z. Hao, Effective desalination by capacitive deionization with functional graphene nanocomposite as novel electrode material, Desalination 299 (2012) 96-102.

80. H. Li, L. Pan, T. Lu, Y. Zhan, C. Nie, and Z. Sun, A comparative study on electrosorptive behavior of carbon nanotubes and graphene for capacitive deionization, Journal of Electroanalytical Chemistry 653 (2011) 40-44. 
81. Y.-J. Kim and J.-H. Choi, Selective removal of nitrate ion using a novel composite carbon electrode in capacitive deionization, Water Research 46 (2012) 6033-6039.

82. Y.-J. Kim, J.-H. Kim, and J.-H. Choi, Selective removal of nitrate ions by controlling the applied current in membrane capacitive deionization (MCDI), Journal of Membrane Science 429 (2013) 52-57.

83. O.N. Demirer, R.M. Naylor, C.A. Rios Perez, E. Wilkes, and C. Hidrovo, Energetic performance optimization of a capacitive deionization system operating with transient cycles and brackish water, Desalination 314 (2013) 130-138. 